\title{
Reflection as a Strategy for Teaching Performance-Based Assessment
}

\author{
Moira A. Fallon \\ State University of New York-College at Brockport \\ Susan C. Brown \\ University of Central Florida \\ Blaine C. Ackley \\ University of Portland
}

\begin{abstract}
Educational reform has provided an impetus for teachers to use more authentic assessment in the classroom, having students demonstrate understanding or knowledge through the performance of tasks or skills. Performance-based assessment (PBA) is a concept that inservice teachers and preservice teachers themselves need to understand and use. In this study the authors identify one critical component for PBA participants, that of self-evaluation using the reflective process. Results show that the process of self-evaluation using reflection is critical to concrete aspects of PBA and has implications for schools, teachers, and students. Several self-reflective activities are presented and qualitative findings are discussed.
\end{abstract}

Educational reform has directed a number of initiatives for teachers to use authentic assessment in the K-12 classrooms. These initiatives have caused teachers to rethink their assessment practice and how it relates to instruction (Marzano \& Kendall, 1996). The result has been the growing classroom use of a more authentic assessment in which students demonstrate understanding or knowledge through the performance of skills. Many teachers feel that this type of assessment requires students to apply their knowledge and skills to solve realistic problems that they will encounter in real life (Tombari \& Borach, 1999). The result has been the incorporation of authentic assessment in the public schools (Diamond, 1998).

Authentic assessment, or performance-based assessment (PBA) as it is known in some states, is a concept with accompanying skills that teachers are scrambling to understand and apply themselves before using PBA with their

Moira Fallon is an Associate Professor at the State University of New York-College at Brockport. Her area of specialization is childhood special education. Susan Brown is an Assistant Professor at the University of Central Florida where she teaches classes in cultural diversity and human development. Blaine Ackley is an Associate Professor at the University of Portland with an expertise in assessment and secondary education. 
own students. As school district leaders restructure their curricula, they must ensure that their teachers are trained in the assessment of learner goals or standards using appropriate PBA tasks and accompanying scoring guides (Burke, 1994). In addition, teachers must be able to work with their own students in helping them set criteria and then assess their own performances according to the criteria (Gregory, Cameron, \& Davies, 1997). The problem is that teacher education institutions need to be prepared to create courses about PBA knowledge and skills or school districts need to create in-depth workshops that do the same.

However, navigating the journey of understanding and applying PBA techniques in school settings require that teachers themselves reach a destination of ownership and reflective voice. The constructivist approach to learning is founded on this idea that the learners create new meaning by connecting what they have already learned and experienced with what they are currently learning (Bacon \& Bloom, 1995; McLaughlin \& Vogt, 1996). According to Schon $(1983,1987)$, such self-reflection is central to making meaning of any learning experience. Knowing this, the question was developed: How can we use self-reflection to equip teachers with the skills they need to design PBA that can be used as either part of their assessment of instruction or in high stakes testing?

For self-development as teachers, individuals need to reflect on their teaching-learning experiences while they occur (reflection-in-action) and after they have occurred (reflection-on-action). They then must form theoretical framework related to the experiences, making adjustments in their understanding and subsequent behavior. Killion and Todnem (1991) extend Schon's concept with reflection-for-action, using reflection to anticipate future experiences and their possible consequences. In fact, some researchers recognize reflection as a switch in the mind's operation. As the mind monitors an action, in the very midst of this action, the mind switches to reflection and begins to wonder what is happening (Long, 1999).

The focus of this paper is on self-evaluation using the reflective process, which the authors consider a critical component for any course or indepth workshop about PBA. We collaboratively designed a PBA course with self-reflection embedded as a critical element. The foundation of the course was a strand of self-reflection that linked the very real, and sometimes messy, use of knowledge in the act of performance. This self-reflection process comes directly from the research literature on the self-evaluation process using reflection. According to O'Laughlin (as cited in Bacon \& Bloom, 1995), the fundamental shift in the paradigm mentioned above, and perhaps the ultimate challenge, is to offer learning opportunities that allow the PBA participants to experience ownership of their own learning and to discover the reflective voices that allow them to express their thoughts and experiences. 
It is for these reasons that we embedded within our course an entire strand on self-reflection. The strand included such evaluative activities as keeping a journal on concepts mastered, engaging in dialogue with reflective feedback of peer editors, tracking individual progress towards professional goals, and mapping the evolution of thought processes.

\section{Question}

This study of PBA using reflection was an exploratory one. Specifically, the authors were interested in finding whether a self-reflection strand embedded into a course on PBA for inservice level K-12 teachers would result in more effective learning about PBA and deeper understanding of the assessment issues in designing PBA tasks and accompanying scoring guides.

\section{Implementing the Process}

All participants were enrolled in M.Ed. programs through the same university (although the sites were different), and all were experienced teachers. The oneweek, two-credit course was offered several times during a two-year period.

\section{The Framework}

The framework for the one-week PBA course was that each participant must design and implement a PBA task and scoring guide for use in their own K-12 classroom setting. The PBA task must be based on district standards and curriculum. We also considered the importance of grounding theory in practice by having the participants plan for their own classrooms. The participants were led through the design part of the course using direct instruction, questioning, group discussion, and simulations. We deliberately chose tools and assignments that were open-ended and involved participants as both teachers and learners. Participants were then paired with one another, across content areas and grade levels, to act as peer editors and evaluators.

The authors collaborated to develop the reflective tools and assignments for the strand, using our understanding of self-reflection as a process and our recognition that any PBA must include self-reflection as a component. Throughout the course, we used a spiraling cycle of planning, action, and revision to guide the self-reflection process for the teachers' learning of PBA knowledge and skills. We felt that the continuous use of deliberate reflection would lead to deeper understanding of the assessment issues involved in PBA for both the participants and their students. For us, this self-reflection strand was a key mechanism for developing the reflection-inaction type of critical analysis. 


\section{Self-Reflection Strand Activities}

The self-reflection strand is composed of four reflection tools. One of the tools is used at both the beginning and end of the course. The others are developed for use throughout the PBA learning at designated intervals. The first reflection tool is the "Professional Action Plan" (see Figure 1). At the beginning of the PBA course, the participants are asked to set personal goals for their learning. The goals are updated throughout the PBA course. This goal setting means that participants will individualize the instruction they receive to their own needs and the needs of their students. Prior to the start of the course, the participants are asked to complete the following phrase, "At the beginning of this assessment course, I believe that performance assessment is ..." At the end of the course, participants are asked to revisit the same phrase, without seeing their initial effort. They are then given the first draft and allowed to compare the two definitions of PBA.

Figure 1 - Professional Action Plan

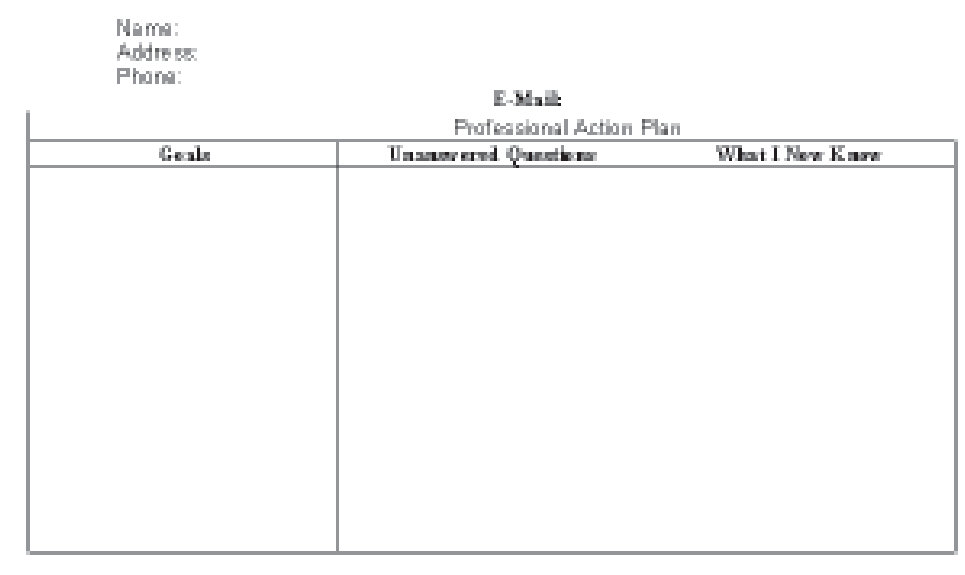

Another self-reflection tool is the "Learning Log" (see Figure 2). This reflective tool requires the participants to track their own insights into the PBA learning process. At designated intervals throughout the course, participants are guided to complete entries in their learning logs. Participants need to be given time to write in the learning logs a minimum of once a day. The logs can also be used to track what these insights mean to their practices in assessment and to their students' performances. 
Figure 2 - Learning Log

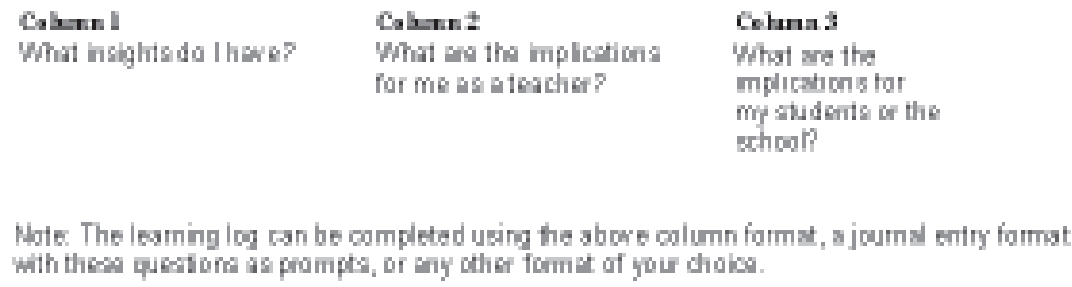

Note. The learning log can be completed using the above column format, a joumal entry format with thesa quesiofa as prompts, of any other format of your chaios.

A final reflective tool is the use of the "Emerging Theory of Action Map" (see Figure 3). In this reflection exercise, participants map their questions, insights, key points, and their emerging model of teacher practices. This tool is used at the end of the course. In it, participants are asked to go back through the course and to map their reflective process in a summary fashion. The other reflective tools may be used to help guide this final product.

Figure 3 - Emerging Theory of Action Map

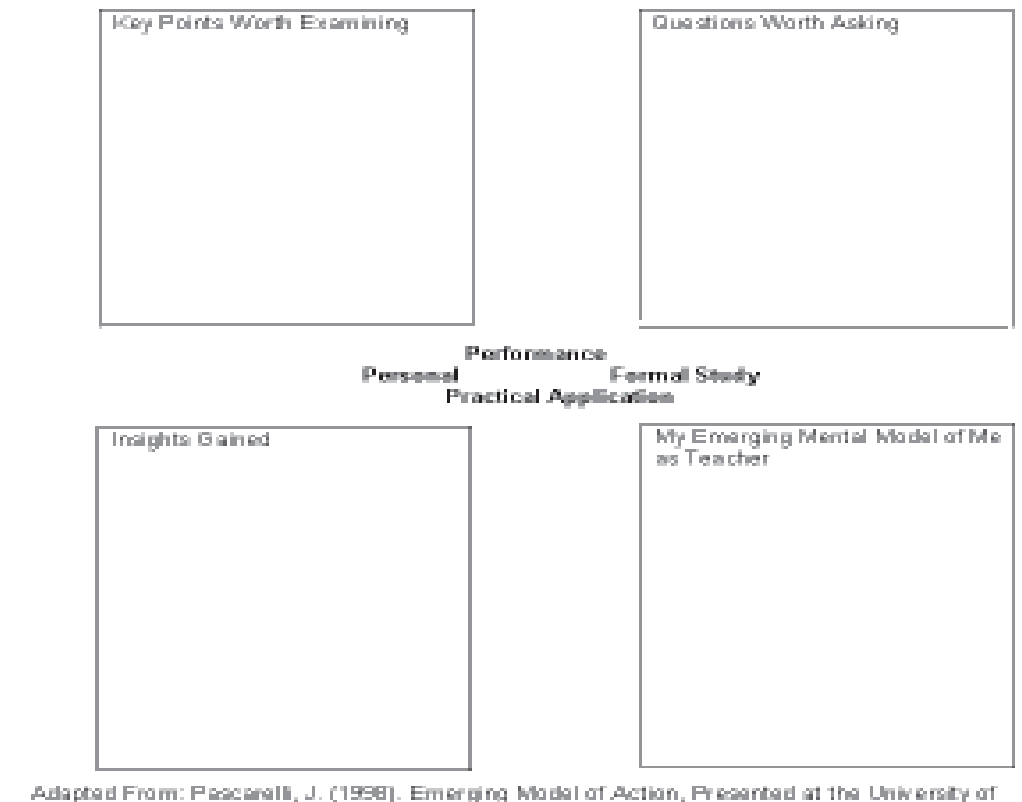




\begin{abstract}
Method
The findings consist of a pre- and post-test of PBA knowledge and concepts and qualitative data on participants' self-evaluation of their reflections as they progressed through a one-week, two-credit course on PBA. The participants reflected upon their knowledge of PBA and their applications on these concepts as they developed a PBA for their individual K-12 classroom settings. The data were gathered over a two-year period of time. The participants $(\mathrm{N}=39)$ included experienced in-service level teachers in the United States, Canada, and Guam, who worked in both public and private school settings.

In order to make sense of the overwhelming amount of data we were able to gather, we reviewed participants' pre- and post test scores on knowledge and attitudes towards PBA, daily reflections, learning logs, professional action plans, and theories of action. For purposes of this study, we computed descriptive data and qualitative themes and patterns from participants' responses. We then selected quotations from participants that represented the themes and patterns we were able to discern (Eisner, 1998; Miles \& Huberman, 1994).
\end{abstract}

\title{
Findings
}

The findings consisted of quantitative analysis on the pre- and post test of participants' knowledge of and attitudes towards PBA, qualitative data on the participants' self-evaluation of their reflections, and descriptive data of the PBA tasks and scoring guides developed by the participants. The results of the paired samples $\mathrm{t}$ test $(t=35.06, p<.0001)$ showed a significant, positive difference in scores from the pre-test to the post test on knowledge about and attitudes towards PBA. The reflection tools used in the gathering the qualitative data were the Learning Logs, the Professional Action Plans, and the Emerging Theory of Action Maps.

The professional action plan assisted the participants in setting goals, tracking unanswered questions, and reflecting upon what they had learned. A summary of response in goal setting is found in Table 1. Seventy-three percent of the participants set goals that were very specific in nature regarding the PBA process. These goals included understanding and using PBA terminology, writing a PBA task that evaluates achievement targets, learning about the specific aspects of PBA, and becoming more effective evaluators. One participant responded, "One of the goals I would like to accomplish ... is to develop and use forms of assessment that truly reflect a child's learning growth." Others said, "...to write clear directions for my PBA" or "To create a 
PBA I will actually use in my class." The unanswered questions that participants worked to answer during the course timeframe included, "Is this the best form of assessment?" or "What things should I be looking for?" and "Where do I find more examples of successful tasks?" Ninety-three percent of the participants achieved their initial goals in the course. However, the majority of these teachers stated that they had replaced the goals with new and more complex ones. Many of them felt they needed to access more resources, to network, and to continue building their skills in the PBA process.

Table 1 - Summary of Responses on Goal Setting Contained in Professional Action Plan

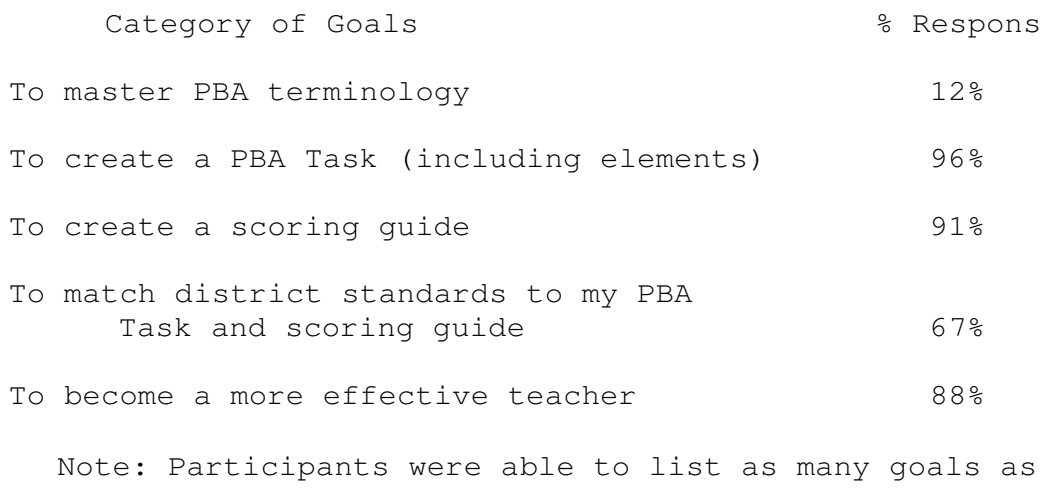

The learning log entries provided a rich source of data on the process of learning about PBA. A majority of participants (68\%) commented on the reflective process using feedback from others in the class. "I learned a lot about clarity and explicitness." "We had to keep in mind that the activity needs to be authentic, engaging, and unusual. The group evaluators helped us identify our weaknesses." "I learned the absolute importance of explicit planning." Many of the entries focused on typical frustrations for teachers, such as, "We tend to focus on the mastery of skills in our students rather than how students will use these skills." or "How do we train parents that there is a better form of assessment?" "Growing up as a student I always thought assessment was paper and pencil, but I have learned it goes beyond that." Another participant said, "I did not find PBA to be as easy as I had assumed. I have to admit I underestimated this project." In answering the question, "Are there implications for my school or students?" seventy-three percent of the participants said it had a strong or important role in how they viewed themselves as a teacher. One participant said, "It has allowed me to look at my 
teaching style and to carefully develop tasks so students can meet any level of objective or standard."

Of the thirty-nine participants in this study, five were unable to develop an emerging model of themselves as a teacher using the PBA process of reflection. Eighty-seven percent $(\mathrm{N}=34)$ did develop that emerging model within the course timeframe. "I see myself more as a coach providing information to my students as the PBA process develops over time." "Incorporating and challenging myself to include culture and to think about adaptations for disabilities." Of the insights into PBA gained by the participants, one said, "Creating good PBA's can be frustrating!" while another commented, "PBA takes more time to create, but students can use them to express more of their learning." One participant said, "Keep revising!" Twelve participants remarked on the ability of the PBA to provide more standardsbased information on students' learning. Seventy-three percent of the participants felt that they were better able to assess individual levels of achievement in diverse learners using a PBA rather than the typical paper and pencil test.

As part of the course, participants designed a PBA task and scoring rubric for use in their K-12 classroom. At the end of the PBA course, these task and rubrics were submitted to a panel of two regional experts on PBA. Each expert independently rated the PBA tasks and scoring guides on a scale of one to five. Seventy-eight percent of the participants received a score of five on the PBA task and scoring guide, while eighteen percent received a rating of four. Four percent of the participants received a rating of three. The inter-rater reliability of the experts was calculated to be .9231 . Each participant received, along with the course grade, a comprehensive written summary of the strengths and weaknesses of the PBA tasks and rubrics. Participants were asked to incorporate the suggested changes before implementing the PBA into the K-12 classroom setting. Thirty eight participants did implement their PBA into their own classroom setting.

\section{Discussion}

As teacher educators, we advocate the use of reflection to enhance the quality of our teacher preparation. We began this exploratory project with an idea for training participants on PBA task and scoring guide. We believe the findings suggest a real need for a comprehensive model that can serve as an integral guide to training PBA evaluators. The results of this project strongly suggest that there is a real need for such a model of helping educators to develop PBA 
and accompanying scoring guides using a strong self-reflection strand as an integral part of the course curriculum.

The participants in this project found that their learning was improved when reflection was integrated into the process of learning to design performance-based assessment tasks and rubrics. We planned for teachers to move beyond simply gaining new technical skills of PBA into a phase of richer understanding of the implications of their practice, both for themselves and their students. We believe that a short, "cookbook recipe" approach to teaching PBA is insufficient. Oversimplification of such a complex learning experience leaves participants with only a superficial knowledge of the development of authentic assessments.

Assessment is more than testing and measurement is more than getting the right answer. The constructivist approach requires that learners connect new learning to the old using learning opportunities that are fostered by their ownership of the process. Such an approach is likened to a kind of puzzlement in which neither the goal nor the means to the goal are stable (Long, 1999); the active experience is the basis for learning, and reflection upon that experience is the active transaction between the learner and the environment. Therefore, in this study, teachers found that discrimination and judgment developed their understanding of PBA, and were in turn enhanced by self-reflection. This is possible only in the real and sometimes messy use of knowledge in the context of the performance itself.

So where do we go from here? If constructivist theory holds true, teachers need to self-reflect regularly so that they become adept at monitoring, assessing, and improving their practice and understanding by discovering their voice and reflecting on their thoughts and experiences (Wiggins \& McTighe, 1998). We believe that the findings of this project may be useful to others in several ways. One way is to incorporate self-evaluation using reflection in other complex learning processes. Another is to adapt the reflection activities to other programs. In understanding such complex issues as PBA, teachers must make meanings of ideas, rather than just using explanations from others in a non-reflective, technical manner. We hope that continued use of the reflective process during such a course will guide participants into continued awareness of their own strengths and shortcomings, thus enhancing their abilities in their own classroom settings. 
Performance-Based Assessment

\section{References}

Bacon, E. H., \& Bloom, L. A. (1995). Beyond the herring sandwich phenomenon: A holistic constructivist approach to teacher education. Journal of Learning Disabilities, 28(10), 636-645.

Burke, K. (1994). The mindful school: How to assess authentic learning (Revised ed.). Arlington Heights, IL: IRI/SkyLight and Publishing, Inc.

Diamond, R. M. (1998). Designing and assessing courses and curricula. San Francisco: Jossey-Bass.

Eisner, E. (1998). The enlightened eye: Qualitative inquiry and the enhancement of educational practice. Upper Saddle River, NJ: Prentice Hall.

Gregory, K., Cameron, C., \& Davies, A., (1997). Setting and using criteria. Merville, BC: Connections Publishing.

Killion, J., \& Todnem, G. (1991). A process for personal theory building. Educational Leadership, 48(6), 14-16.

Long, F. (1999). On teaching reflection. Unpublished paper presented at the biennial conference of International Study Association on Teachers and Teaching, Dublin, Ireland.

Marzano, R. J., \& Kendall, J. S. (1996). A comprehensive guide to designing standards-based districts, schools, and classroom. Alexandria, VA: Association for Supervision and Curriculum Development.

McLaughlin, M., \& Vogt, M. E. (1996). Portfolios in teacher education. Newark, DE: International Reading Association.

Miles, M. B., \& Huberman, A. M. (1994). Qualitative data analysis: An expanded sourcebook ( $2^{\text {nd }}$ ed.). Thousand Oaks, CA: Sage Publications.

Pascareli, J. (1998). Emerging model of action. Paper presented at the University of Portland, Portland, OR.

Schon, D. (1983). The reflective practitioner: How professionals think in action. NY: Basic Books.

Schon, D. (1987). Educating the reflective practitioner: Toward a new design for teaching and learning in the professions. San Francisco: JosseyBass.

Tombari, M., \& Borach, G. (1999). Authentic assessment in the classroom: Applications and practice. Upper Saddle River, NJ: Prentice Hall.

Wiggins, G., \& McTighe, J. (1998). Understanding by design. Alexandria, VA: Association for Supervision and Curriculum Development. 